\title{
DO ALL CREATIVE STIMULI WORK THE SAME? INSIGHTS FROM A WORKSHOP WITH PROFESSIONALS
}

\author{
H. Singh ${ }^{凶}$, N. Becattini and G. Cascini \\ Politecnico di Milano, Italy \\ $\square$ harshika.singh@polimi.it
}

\section{Abstract}

The paper presents a comparative study that explores the effectiveness of creative stimuli to foster the generation of creative ideas in non-trained professionals during a co-creative design session. Solution-related stimuli (e.g. patents or biological strategies) are confronted with problem-based stimuli (e.g. TRIZ contradictions or Ideal Final Result), which are less studied in the literature. The 40 participants to the experimental activity benefited from both kind of stimuli, but the solution-related ones allowed a more comprehensive exploration of the design space.

Keywords: collaborative design, design creativity, idea generation, creative stimuli, open innovation

\section{Introduction}

Environment, the profile of the participants, facilitator skills, and engagement in the design task have a large impact on the outcome of the design activity. Among the others, the kind of creative stimuli (i.e. the stimuli that help in generating creative solutions) proposed during idea generation affect the ideation activity and therefore the final design outcome. This paper presents the results of an early investigation carried out in a co-design workshop involving professionals from industries and academia, where different creative stimuli were proposed in parallel sessions. The workshop was organized within the EU 's Erasmus + project OIPEC (Open innovation Platform for UniversityEnterprise Collaboration) whose main objective was to bring Open-Innovation in SMEs (Small and Medium Enterprises). Collaborative Open Innovation Laboratories (COILabs) were established as a part of OIPEC who aimed to increase the collaboration between universities and enterprises to generate novel products/services or improving existing ones. They are established in Milan (Italy), Grenoble (France), Hebei (China), Lappeenranta (Finland), Moscow (Russia), Tianjin (China) and Vladimir (Russia). COILabs offer training courses to enterprises as well as project-based activities, where university and enterprise work together on real problems. These courses and training are in three major areas; Module A: Tools for idea development and prototyping, Module B: Inventive Design and Design creativity and Module C: Open Innovation and university-enterprise collaboration. Therefore, as a part of COILab Milan activity, a workshop with 5 groups of 7-8 participants from companies and academia was held to test the efficiency of some of the tools offered as a part of COILab curriculum in Module B. The workshop was conducted under the assumption that the creative stimuli could help non-trained designers to be more creative. The expression 'non-trained designers ', 
in this context refers to the professional participants of the activities who have not been exposed to these creative stimuli while approaching a design problem in the past.

Despite the presence of many innovative idea generation tools, companies still use traditional brainstorming (Faure, 2004). Thus, the goal of the workshop was to see the effect of stimulation tools on non-trained designers and the evidence to address these concerns are provided in this paper. Simulating creativity at an early stage of the design process is one of the possible answers to innovate as it involves fewer resources (low risk, low costs, fewer investments etc.) (Malins et al., 2014). It is often taken for granted that stimulation helps in creative thinking, but it is unclear if all stimulation tools produce similar effects on creativity and how effective they are when used by non-trained designers. Expanding the conceptual design space (where problems and solutions are explored) to novices in a field is relatively easy and makes sense to compare different stimuli. However, the purpose of this study is not to check whether the stimuli are effective to produce creative outcomes, but how much they are helpful in expanding the exploration of the design space compared to each other. The potential contribution of the work lies on results that are deduced from the teams of adults working in a company or university, after performing a design task without prior training in this specific area. Since none of the participants was familiar with creativity stimulation tools used, the workshop intended to extend (and measure) their conceptual design space during idea generation.

To explore the effect of stimulation tools on non-trained designers, the work presented in this paper is structured as follows. The subsequent part of the paper consists of the background of the stimuli used. This is followed by the experiment methodology consisting of the structure of the workshop and data processing. The paper in the end presents results, discussion and conclusions summarising the work.

\section{Background}

\subsection{Creative stimuli characteristics}

The studies in the past showed that creative stimuli produce different results on generated ideas depending on their main characteristics. For instance, their effects have been compared by distinguishing different facets of the contents the stimuli embedded. For instance textual vs graphical stimuli (Cardoso et al., 2012), function and context relatedness to the target design domain (Jia et al., 2019), word relatedness (Chiu and Shu, 2012) as well as solutions described in patents coming from "near" and "far" design domains when compared to the target domain (Fu et al., 2013). All the above-mentioned studies aimed at triggering some analogies by exposing the recipient to prior solutions and/or examples of ideas and concepts. On the other hand, literature also presents stimuli referring to more general design heuristics or hints of solution characteristics, such as technical trends of evolution as for Saliminamin et al. (2019). The latter, collect sets of solutions that share one common characteristic (e.g. purpose, behaviour), while the other characteristics are changing over time. This evolutionary trend aims at triggering design by analogy in the target domain, thus helping in mimicking an evolutionary step borrowed from a different context or domain. These stimuli therefore, are not simply stimulating with examples of solutions as the commonalities among the solutions set are the stimulating factors. As described above, literature presents several contributions about the administration of stimuli such as design strategies, examples, precedents (Saliminamin et al., 2019), which are elements belonging to the solution space (Dorst and Cross, 2001). There are fewer studies on the effects of stimuli based on the typical elements of the problem space. Parvin et al. (2017), for instance, leveraged patent contents (describing the solutions) to extract mutually conflicting requirements, which are problem-related characteristics. These, expressed as TRIZ models of contradiction, were used as stimuli for fostering ideation in designers.

\subsection{Creative stimulation for professionals}

Creative stimuli help in producing reasoning by analogy and their effectiveness during the design process have been proved in the past (Goel, 1997 and Kao, 2014). However, the effect of the creative stimuli varies with respect to the profile of the participants (novices or professionals), but it is still underexplored. It is known that the effect of these stimuli on students (novices) vs professionals are 
different. Authors such as Gonçalves et al. (2016), Bonnardel and Marmèche (2004) and Ozkan and Dogan (2013) have worked on seeing how ideas from individual novice and experts differ in terms of their inspirations and analogical thinking while designing. Others have found that the stimuli related to near-field analogies are useful in generating ideas with higher novelty in the case of teams of nontrained designers who were graduate students (Jia et al., 2019). Most of the authors base their findings on results obtained from teams of students, who potentially behave differently than professionals (Chai, 2015). Therefore, it might provide a limitation on the applicability of their findings in 'real-life' scenarios. Only some studies have been found with company employees/professionals for testing the effectiveness of creative stimuli on idea generation (Kennedy et al., 2018, Howard et al., 2010 and Saliminamin et al., 2019). As this number is very limited, there is a clear need to retrieve data from the application of creative stimuli by professional participants. The previous studies have often missed addressing the above-stated point and thus the authors believe that gaining insights in the 'actual' operational context can have a stronger impact.

\subsection{Investigated question}

According to the limitations described in the previous subsections, the paper presents a preliminary attempt to compare the effect of stimuli that presents characteristics from the problem and solution space. Moreover, section 2.1 also showed that most of the existing studies focus on stimuli that trigger inspiration through concrete examples like patented solutions or requirements. Only a few of them deals with stimuli with abstract characteristics. Therefore, the authors wanted to explore the performance of stimuli according to both these dimensions that characterize stimuli (Problem/solution and abstract/concrete), as shown in Figure 1. The goal is to check their capability to redirect the idea generation process of co-designers towards unexplored areas of the design space. Stimuli can be, therefore, characterized according to the four-quadrant diagram. SCAMPER (Eberle, 2008), TRIZ models of contradictions, TRIZ Ideal Final Result and Resources (Baldussu et al., 2011, Cascini, 2012 and Saliminamin et al., 2019), natural sources of inspiration as biological strategies (Kennedy, 2018) and patents (Fu et al., 2013) were selected as sources of stimuli. In this case, natural sources of inspiration as biological strategies and patents were classified as concrete stimuli. SCAMPER, TRIZ models of contradictions, and TRIZ Ideal Final Result and Resources were considered as abstract stimuli. In the case of problem-focused stimuli, TRIZ Contradiction and TRIZ Ideal Final Result and Resources were considered as they help the designer to focus the attention to (re) defining the design problem. Stimuli such as SCAMPER, biological strategies and patents were considered solution-based due to their nature of focusing designer 's attention to generate solutions than reframing the problem. The choice not to address stimuli in the quadrant Problem/Concrete is mainly due to the nature of the design task presented in the next section. The selection of this kind of stimuli appears to be more meaningful to address open problems, which require the designer to figure out new requirements for the solution, rather than addressing already existing ones as for the design task presented in Section 3.

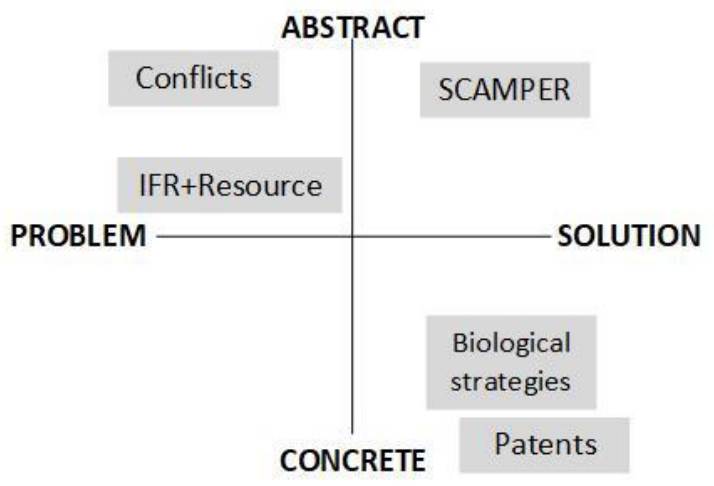

Figure 1. Categorisation of stimuli

Consistently with the limitations mentioned in section 2.2, the authors also wanted to compare if and how the above kind of stimuli trigger a different exploration of the solution space when used with non- 
trained professionals. As it is known that exploration of the design space (measured through a variety of ideas) is one of the relevant metrics to characterize creative behaviour (e.g. divergent thinking) and it yields results about ideation effectiveness (Shah et al., 2003).

In other words, the paper addresses the following research question: how effective are problem/solution and abstract/concrete stimuli with non-trained professionals in redirecting idea generation towards unexplored areas of design space?

\section{Methodology}

\subsection{Experiment setting}

\subsubsection{Workshop structure}

The workshop was held at Makers Hub in Milan, which provides workspaces to professionals or hobbyists during all phases of their project (from concept to commercialisation). This place was chosen due to its dynamic and collaborative nature to motivate participants (Fechter et al., 2016). There were five groups (named from A to E) of 7-8 people with a facilitator for each group (Figure 2 shows one of the groups in action). The facilitator had to set the pace for the activity, help its group in understanding the stimulation tool allotted and collect the chosen ideas for final presentation. They were professors and $\mathrm{PhD}$ students who are experts in the field of methods and tools for creative design. They have delivered or have been a part of training and courses to the students and professionals. The participants were from companies and academia from all over Europe, Russia and China. The majority of the participants were male. They did not have any background or prior training in creative stimulation tools provided during the workshop (confirmed through the feedback questionnaire collected at the end of the workshop). The groups were formed such that there was a balance of the academic and company profiles of the participants in each team. The teams were composed of participants from different countries, so English was the language of conversations. These participants self-volunteered to participate in this workshop hoping to learn some of the idea stimulation techniques in a concise workshop, which they would use in companies or academia.

The purpose was to check the effectiveness of stimuli to drive the exploration of the design space towards areas that are less intuitive to access during ideation. The experiment was organized into two rounds for ideation (60 minutes each) with a 20-minute break between rounds, as for Jia et al. (2019) and Saliminamin et al. (2019). The first round is carried out with no stimulation, beyond the crossfertilization due to idea exchange of typical brainstorming. The second round is carried out with the administration of creative stimuli. The outcomes of the first round per se allow for comparing the homogeneity of results among groups with no stimulation. This verifies that no group significantly performs differently from others, due to their natural talent. The duration of the first round is also planned so that most of the idea generation potential per group gets exhausted, as typically the rate of good/highly promising ideas decreases after 30 minutes (Howard et al., 2010). The second round, in turn, produces data that can be compared across groups or within the same group with reference to the first round. In particular, the differences between the second and the first round (for the same group) will be used as the relevant metrics to evaluate the effectiveness of stimuli to redirect the focus of idea generation towards previously unexplored areas of the solution space. The materials provided were post-its, idea capture template, poster-size paper for presenting chosen ideas and sharpies/markers to facilitate smooth co-design activity (Lucero et al., 2012).

\subsubsection{Administration of stimuli}

The 5 groups were exposed to creative stimuli as for Section 2.3. Each team for the second design round had one kind of stimuli for idea generation. Table 1 summarizes how stimuli were administered and their main contents for creative stimulation. As detailed in the right column of Table 1, these stimuli range a large set of different contents. This choice aims at providing a more comprehensive viewpoint on creative stimuli. It also enables highlighting the potential differences different stimuli could trigger on the exploration of the design space during the stimulated session (second round). 
Table 1. Stimuli used during the workshop

\section{Group Stimuli}

A

B

C

$\mathrm{D}$

E

Patents
Biological strategies from AskNature.org (The Biomimicry Institute, 2018)

TRIZ Contradiction (Baldussu et al., 2011 and Parvin, 2017)

TRIZ Ideal Final Result and Resources (Altshuller, 1984)

SCAMPER (Substitute, Combine, Adapt, Modify (Also magnify and minify), Put to another use, Eliminate, and Reverse) (Eberle, 2008)

\section{Content}

Strategies of living things to address survival problems

The first page of patented solutions with text and graphics

Set of incompatible requirements and heuristics to address these conflicts

Ideal technical systems and exploitation of available systems ' resources

Heuristics to change some features of an existing product or idea/concept

\subsubsection{Design task}

The design problem that they had to solve is given below:

"In cold countries, thick ice plates happen to form on lorry roofs; accidental ice falls provoke serious accidents. The typical solution to prevent these accidents consists of stopping the trucks in dedicated stations to clean their roofs before proceeding the drive. Unfortunately, this determines significant time losses and lorry drivers are quite concerned about that. Another solution adopted in the past was based on a sloping roof; however, this solution has been discarded because it implies a not negligible reduction of the volume usable for the cargo (the maximum height is limited by traffic laws)". The task could have been challenging, as there is no existing solution. At the same time, it would provide plenty of room and opportunity to come up with creative solutions without being influenced by the already available market/web solutions.

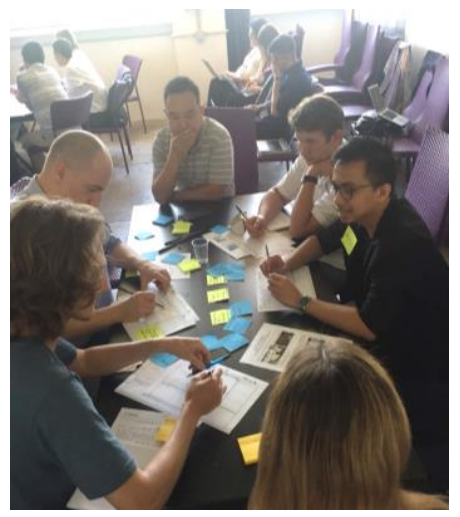

Figure 2. Group D filling the idea capture template during the workshop

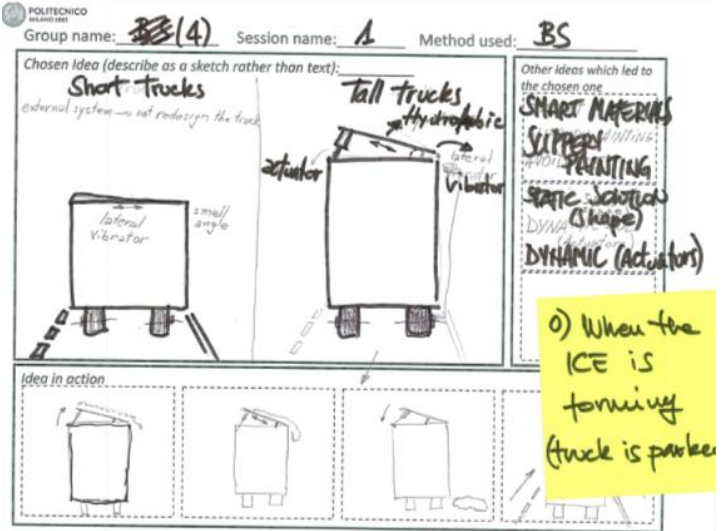

Figure 3. One of the free brainstorming sketch of group $D$

\subsection{Experimental data management}

\subsubsection{Data collection}

Experimental data for the assessment of the triggered divergent thinking were captured as ideas through tailored templates, which each group was supposed to fill after the free brainstorming session and the session with creative stimuli. Figure 3 shows an exemplary concept and related data collected in the template. Each form included the main space to draw the concept with details, a storyboard to provide a dynamic description of the idea in action and a third area to take note of inspiration sources. 
All the facilitators were also advised to take pictures of the post-it notes before the final ideas are selected after each round to see evolution and quantity of ideas generated.

\subsubsection{Characterization of the design space with coding schemes}

In order to explore the effectiveness of stimuli to foster divergent thinking in professionals from a set of ideas generated, the outcomes of the two sessions have to be coded to capture their variety between the two rounds of the experiment. This requires to characterize the design space (solution space) based on mutually independent variables that are capable of describing different details of the proposed ideas. The authors chose to describe the solution space by four mutually exclusive sets of characteristics. This was done so that differences between the generated concepts can emerge and provide evidence on how the focus of ideas generated changed between the two rounds. This follows the assumption that the difference between rounds corresponds to a positive effect of the stimuli on the exploration of the design space. The ideas were coded according to the following four dimensions. The purpose of the proposed solution was not considered as it was already set by the design task given to the groups. The four dimensions that characterize the design space and, thus, the proposed solutions are:

a) The space or the structural level of detail of the solution

b) The solution-working time frame

c) The strategy that the solution exploits to address the problem

d) The field(s) of interaction that form the working principle, needed to produce the required effects

Beyond the purpose of the solution, which is defined by the design task, these dimensions describe the idea/concept generated to address the problem by referring to its structural (a) and behavioural (c and d) features, thus spanning the three ontological variables of the FBS ontology (Gero and Kannengiesser, 2004). Moreover, the design space has been also mapped in terms of the time (b), as this can complement the viewpoint on stimuli 's effectiveness to trigger system thinking, which is consistent with the horizontal axis of TRIZ System Operator (Altshuller, 1984). This time dimension is useful to understand how stimuli help in generating solutions related to a particular condition of the problem that is time-dependent (described as b1,b2 and b3 in Table 2).

\section{Table 2. Coded levels and sub levels}

\section{Dimension of the solution space explored in the two rounds}

a) The structural level of scale of the solution

b) The solution-working time frame

c) The strategy that the proposed solution leverages to address the problem

d) The field of interaction which describes the working principle of the solution
Sub-codes for each scheme of coding

- a1) Environment of the system

- a2) System

- a3) System components/parts

- b1) Before ice grows (Prevention),

- b2) During ice formation

- b3) Melting of ice/Removal of ice (Cure)

- c1) Branch, Channel, Connect

- c2) Control Magnitude, Provision, Signal

- c3) Convert, Support

- d1) Gravitational, Mechanical, Acoustic

- d2) Thermal, Chemical, Electrical,

Magnetic, Electro-magnetic,

- d3) Biological, Nuclear

\author{
IRR-Fleiss 's \\ Kappa for \\ two coders \\ 0.75

The sub-codes (refer to Table 2) describing the structural level or the space dimension that distinguishes among the solutions that belong to the contextual environment of the system (a1), dealing with the whole technical system (a2) or simply leveraging few parts/components (a3). Sub-codes about time distinguish ideas that address the root cause (b1), the emergence of the problem (b2) or its resultant effects (b3). To map the behaviour, one set of sub-codes describes the strategy for the solution (c). These sub-codes are based on the classes (primary) of the NIST Functional Basis (Hirtz et al., 2002). These 8 basic functions 
have been further clustered into 3 strategies used as sub-codes: Strategy 1 - Moving ice from the roof (c1 - Branch, Channel, Connect), Strategy 2 - Reducing ice thickness (c2 - Control Magnitude, Provision, Signal) and Strategy 3 - Melt the ice (c3 - Convert, Support). The sub-codes describing the last dimension consider the field(s) of interaction leveraged by the working principle that the solution embeds. These codes have been conveniently organized according to the TRIZ-based classification of interaction fields (Altshuller, 1984). The first sub-code considers interactions based on the mechanical field (d1: mechanics, gravity, acoustics...); the second one deals with electromagnetic interactions (d2: thermal, electric, magnetic) and the third sub-code is for remaining fields (d3, e.g. biological, nuclear). Two coders evaluated the set of the ideas generated in the two rounds. The Inter-Rater Reliability (IRR) of the coded data has been estimated using of Fleiss 's Kappa statistics, whose values are summarized in the last column of Table 2. Values above 0,6 indicate substantial agreement (Landis and Koch, 1977).

Then, to answer the research questions mentioned at the end of section 2, it is necessary to observe how much the distribution of ideas generated during the second stage of the workshop (when groups used creative stimuli) differ from the ones generated during the first stage. To deal with comparable figures across groups, the ideas were normalized to the overall number of generated ideas. The ratio of generated ideas per each code provides a clear indication of how the ideas are distributed in the design space during each of the two stages of ideation. Differences between codes measured in the two stages (delta values) show how the stimuli in the second round made the generated ideas diverse from those intuitively generated during the first round. The variance of these delta values estimates the effectiveness of stimuli in redirecting the thinking process of co-designers (higher variance is for higher effectiveness).

\section{Results and discussion}

Tables 3 to 6 collects the results according to the metrics described at the end of Section 3. The variance (stated in the lowest row of each table) has been measured on the proportion of distribution of ideas across the sub-codes, within each coding scheme. Moreover, it is a quadratic estimator. Thus, variance yields values close to zero when differences between the rounds are small. On the other hand, the larger the variance is, the more significant is the effect of stimuli in shifting the viewpoint during idea generation towards areas of the design space that were not considered during the free brainstorming stage. Table 3 and 4 present the results of the two-ideation stages (free brainstorming and stimulated sessions) organized according to the stimuli 's degree of abstraction; (varying from concrete to abstract stimuli). Similarly, Table 5 and 6 present the results organized by stimuli based on whether they deal with aspects related to problems or solutions.

Table 3. Distribution of generated ideas in the design for groups dealing with concrete stimuli (Round 1 - Free brainstorming, Round 2 - Patents and Biological stimuli)

\begin{tabular}{cccccccccccccc} 
GROUPS & \multicolumn{2}{c}{$\begin{array}{c}\text { Structural level of the } \\
\text { A and B }\end{array}$} & \multicolumn{2}{c}{ proposed solution } & \multicolumn{3}{c}{$\begin{array}{c}\text { Solution-working time } \\
\text { frame }\end{array}$} & \multicolumn{3}{c}{$\begin{array}{c}\text { Strategy to address } \\
\text { the problem }\end{array}$} & \multicolumn{3}{c}{$\begin{array}{c}\text { Field of interaction of } \\
\text { the working principle }\end{array}$} \\
& $\mathrm{A} 1$ & $\mathrm{~A} 2$ & $\mathrm{~A} 3$ & $\mathrm{~B} 1$ & $\mathrm{~B} 2$ & $\mathrm{~B} 3$ & $\mathrm{C} 1$ & $\mathrm{C} 2$ & $\mathrm{C} 3$ & $\mathrm{D} 1$ & $\mathrm{D} 2$ & $\mathrm{D} 3$ \\
Round 1 & 0.50 & 0.50 & 0 & 0.43 & 0.14 & 0.43 & 0.33 & 0.50 & 0.17 & 0.50 & 0.50 & 0 \\
Round 2 & 0.33 & 0 & 0.67 & 0.20 & 0.20 & 0.60 & 0.40 & 0.20 & 0.40 & 0.20 & 0.20 & 0.60 \\
Delta & -0.17 & -0.50 & 0.67 & -0.23 & 0.06 & 0.17 & 0.07 & -0.30 & 0.23 & -0.30 & -0.30 & 0.60 \\
Variance & & $\mathbf{0 . 3 6 1}$ & & & $\mathbf{0 . 0 4 2}$ & & & $\mathbf{0 . 0 7 4}$ & & & $\mathbf{0 . 2 7 0}$ &
\end{tabular}

Table 4. Distribution of generated ideas in the design for groups dealing with abstract stimuli (Round 1 - Free brainstorming, Round 2 - TRIZ Conflicts, IFR+Resources, SCAMPER as stimuli)

\begin{tabular}{cccccccccccccc} 
GROUPS & \multicolumn{3}{c}{$\begin{array}{c}\text { Structural level of the } \\
\text { proposed solution }\end{array}$} & \multicolumn{4}{c}{$\begin{array}{c}\text { Solution-working time } \\
\text { frame }\end{array}$} & \multicolumn{3}{c}{$\begin{array}{c}\text { Strategy to address the } \\
\text { problem }\end{array}$} & \multicolumn{3}{c}{$\begin{array}{c}\text { Field of interaction of } \\
\text { the working principle }\end{array}$} \\
& $\mathrm{A} 1$ & $\mathrm{~A} 2$ & $\mathrm{~A} 3$ & $\mathrm{~B} 1$ & $\mathrm{~B} 2$ & $\mathrm{~B} 3$ & $\mathrm{C} 1$ & $\mathrm{C} 2$ & $\mathrm{C} 3$ & $\mathrm{D} 1$ & $\mathrm{D} 2$ & $\mathrm{D} 3$ \\
Round 1 & 0.00 & 0.33 & 0.67 & 0.27 & 0.27 & 0,45 & 0,50 & 0.40 & 0.10 & 0.56 & 0.33 & 0.11 \\
Round 2 & 0.00 & 0.56 & 0.44 & 0.09 & 0.18 & 0.73 & 0.40 & 0.20 & 0.40 & 0.55 & 0.27 & 0.18 \\
Delta & 0.00 & 0.22 & -0.22 & -0.18 & -0.09 & 0.27 & -0.17 & 0.10 & 0.07 & -0.01 & -0.06 & 0.07 \\
Variance & & $\mathbf{0 . 0 4 9}$ & & & $\mathbf{0 . 0 5 8}$ & & & $\mathbf{0 . 0 2 1}$ & & & $\mathbf{0 . 0 0 4}$ &
\end{tabular}


Table 5. Distribution of generated ideas in the design for groups dealing with solution-related stimuli (Round 1 - Free brainstorming, Round 2 - SCAMPER, Patents, Biological stimuli)

GROUPS Structural level of the Solution-working time Strategy to address the Field of interaction of $\mathrm{A}, \mathrm{B}$ and $\mathrm{E}$ proposed solution frame problem the working principle

$\begin{array}{ccccccccccccc} & \text { A1 } & \text { A2 } & \text { A3 } & \text { B1 } & \text { B2 } & \text { B3 } & \text { C1 } & \text { C2 } & \text { C3 } & \text { D1 } & \text { D2 } & \text { D3 } \\ \text { Round 1 } & 0.33 & 0.44 & 0.22 & 0.50 & 0.10 & 0.40 & 0.33 & 0.56 & 0.11 & 0.44 & 0.44 & 0.11 \\ \text { Round 2 } & 0.22 & 0.11 & 0.67 & 0.11 & 0.22 & 0.67 & 0.40 & 0.40 & 0.20 & 0.44 & 0.22 & 0.33 \\ \text { Delta } & - & -0.33 & 0.44 & -0.39 & 0.12 & 0.27 & 0.07 & -0.16 & 0.09 & 0.00 & -0.22 & 0.22 \\ & 0.11 & & & & & & & & & & & \\ \text { Variance } & & \mathbf{0 . 1 6 1} & & & \mathbf{0 . 1 1 9} & & & \mathbf{0 . 0 1 8} & & & \mathbf{0 . 0 4 9} & \end{array}$

Table 6. Distribution of generated ideas in the design for groups dealing with problem-related stimuli (Round 1 - Free brainstorming, Round 2 - TRIZ Conflicts and IFR+Resources)

\begin{tabular}{cccccccccccccc}
$\begin{array}{c}\text { GROUPS } \\
\text { C and D }\end{array}$ & \multicolumn{3}{c}{$\begin{array}{c}\text { Structural level of the } \\
\text { proposed solution }\end{array}$} & \multicolumn{4}{c}{$\begin{array}{c}\text { Solution-working time } \\
\text { frame }\end{array}$} & \multicolumn{3}{c}{$\begin{array}{c}\text { Strategy to address the } \\
\text { problem }\end{array}$} & \multicolumn{3}{c}{$\begin{array}{c}\text { Field of interaction of } \\
\text { the working principle }\end{array}$} \\
& $\mathrm{A} 1$ & $\mathrm{~A} 2$ & $\mathrm{~A} 3$ & $\mathrm{~B} 1$ & $\mathrm{~B} 2$ & $\mathrm{~B} 3$ & $\mathrm{C} 1$ & $\mathrm{C} 2$ & $\mathrm{C} 3$ & $\mathrm{D} 1$ & $\mathrm{D} 2$ & $\mathrm{D} 3$ \\
Round 1 & 0.00 & 0.33 & 0.67 & 0.13 & 0.38 & 0.50 & 0.57 & 0.29 & 0.14 & 0.67 & 0.33 & 0.00 \\
Round 2 & 0.00 & 0.67 & 0.33 & 0.14 & 0.14 & 0.71 & 0.29 & 0.43 & 0.29 & 0.43 & 0.29 & 0.29 \\
Delta & 0.00 & 0.33 & -0.33 & 0.02 & -0.23 & 0.21 & -0.29 & 0.14 & 0.14 & -0.24 & -0.05 & 0.29 \\
Variance & & $\mathbf{0 . 0 1 1}$ & & & $\mathbf{0 . 0 5 0}$ & & & $\mathbf{0 . 0 6 1}$ & & & $\mathbf{0 . 0 7 0}$ &
\end{tabular}

Concerning the research question, the comparison of variance between groups dealing with abstract- and concrete-stimuli show that the results are not uniform across the 4 coding schemes that characterize the design space. It was noticed that the variances are higher for concrete stimuli than abstract ones, for 3 out of 4 coding schemes. This comparison of variances shows a particular effectiveness of concrete stimuli, compared to abstract ones, to redirect the viewpoint during idea generation for two codes: the one dealing with the structural level of the proposed solution $(0.361 \mathrm{vs} 0.049)$ and the one that considers the field of interaction that the working principle leverages to address the problem $(0.270$ vs 0.004$)$. On the contrary, the results for the other two coding schemes are of the same order of magnitude, suggesting that the effectiveness of the two clusters of stimuli can be considered similar (and not particularly effective, as the values are close to zero). Regarding concrete-abstract stimuli, unfortunately, data did not provide evidence for drawing reliable conclusions as for the previous analysis. Nevertheless, solutionbased creative stimuli can be claimed to be more effective than problem-based ones for two of the considered coding schemes, namely at the structural level of the proposed solution (0.161 vs 0.011$)$ and the time-frame level $(0.119$ versus 0.050$)$.

With a more comprehensive perspective, the results support the conclusion that solution-based and concrete stimuli are more effective when used by non-trained professionals. This experimental evidence could depend on the nature of the stimuli, as they are less difficult to interpret than problemrelated or abstract ones. The latter would require a two-step thinking for ideation: first, they need to be interpreted, and then they need to be linked to a domain that is different from the initial one. In the case of problem-based stimuli, the ideas have to be translated into a working solution. In the case of abstract stimuli, they are required to be brought back into the context of the design task.

\section{Conclusion}

Controversial results are present in the literature on stimuli and creativity. It is widely believed that stimuli produce creative results, irrespective of the profile of the participants. Therefore, one of the questions, which was answered in this paper, was about the relationship between stimuli type and nontrained designers. The work dealt with providing initial steps on how to structure stimuli with respect to the profile of the participants. The stimulation tools selected were according to two orthogonal axes mentioned in the paper, problem-solution and abstract-concrete. The ideas were collected from the COILab workshop where the participants generated concepts in two sessions (free Brainstorming and Stimulated sessions). Two experts in the field coded the ideas to analyse their position in the design 
space according to the coding schema. The coding schema to determine design space exploration was according to the four dimensions that characterize the design space; the structural level of the solution, time frame to address the problem, strategy to address the problem and the field of interaction of the working principle used in the idea. These four dimensions used as coding schemes were further divided into three sub-levels, so that time and space dimension along with the detail level of the concepts generated were taken into account. The distribution across the design space of ideas generated during the two sessions was calculated. The findings addressing the research question (how effective are problem/solution and abstract/concrete stimuli with non-trained professionals in redirecting idea generation towards unexplored areas of design space?) were identified. While analysing the difference between the two stages, it was found that the second round (using stimuli for ideation) made the generated ideas more diverse from those intuitively generated during the first round. Overall, the results suggest that it might be effective to use solution-based and concrete stimuli with non-trained professionals. However, why these stimulation tools behaved in this manner or why there was significant difference in the space dimension than others, still needs further investigation. Nevertheless, one possible reason could be that stimuli like SCAMPER and IFR + Resources leveraged more the space dimension of the design space than other stimuli.

The differences in facilitators ' personality and their personal background might affect the way they facilitated the group activity, this aspect was not considered and it can be considered one of the limitations of these findings. Moreover, the work presented here does not take into account the difference in the modes of creative stimuli (e.g. given as images or text and/or the way they are delivered) as it was out of the scope of this study. The study was done on a small scale where the groups were heterogeneous. Additionally, the reason behind the difference in the group idea generation could also be due to the personal motivation of an individual or groups, was not considered.

Overall, the aim of the paper was not to tell which tool is better in producing creative results instead, the focus was on explaining how stimulation tools help to explore the design space. Furthermore, the paper also proposes a new approach to characterise design space into four new dimensions to capture idea effectiveness.

\section{Acknowledgements}

This workshop conducted was a part of COILab event in Milan. COILabs are part of OIPEC project (Open innovation Platform for University-Enterprise Collaboration) which is a collaborative educational project funded by the Erasmus+ Program of the European Union (OIPEC, 2016).

\section{References}

Altshuller, G.S. (1984), Creativity as an exact science: the theory of the solution of inventive problems, Gordon and Breach, Amsterdam.

Baldussu, A., Becattini, N. and Cascini, G. (2011), "Network of contradictions analysis and structured identification of critical control parameters", Procedia Engineering, Vol. 9, pp. 3-17. https://doi.org/ 10.1016/j.proeng.2011.03.096

Bonnardel, N. and Marmèche, E. (2004), "Evocation processes by novice and expert designers: Towards stimulating analogical thinking”, Creativity and Innovation Management, Vol. 13 No. 3, pp. 176-186. https://doi.org/10.1111/j.0963-1690.2004.00307.x

Cardoso, C., Gonçalves, M. and Badke-Schaub, P. (2012), "Searching for inspiration during idea generation: pictures or words?", Proceedings of DESIGN 2012, the 12th International Design Conference, Dubrovnik, Croatia.

Cascini, G. (2012), "TRIZ-based anticipatory design of future products and processes", Journal of Integrated Design \& Process Science, Vol. 16 No. 3, pp. 29-63. https://doi.org/10.3233/jid-2012-0005

Chai, C. et al. (2015), "Behavioral analysis of analogical reasoning in design: Differences among designers with different expertise levels", Design Studies, Vol. 36, pp. 3-30. https://doi.org/10.1016/j.destud.2014.07.001

Chiu, I. and Shu, L.H. (2012), "Investigating effects of oppositely related semantic stimuli on design concept creativity", Journal of Engineering Design, Vol. 23 No. 4, pp. 271-296. https://doi.org/10.1080/09544828. 2011.603298

Dorst, K. and Cross, N. (2001), "Creativity in the design process: co-evolution of problem-solution", Design Studies, Vol. 22 No. 5, pp. 425-437. https://doi.org/10.1016/S0142-694X(01)00009-6

Eberle, B. (2008), Scamper: Creative Games and Activities for Imagination Development, Prufrock Press. 
Faure, C. (2004), "Beyond Brainstorming: Effects of Different Group Procedures on Selection of Ideas and Satisfaction with the Process", The Journal of Creative Behavior, Vol. 38 No. 1, pp. 13-34. https://doi.org/10.1002/j.2162-6057.2004.tb01229.x

Fechter, M. et al. (2016), "Impact of collaborative space on team work in engineering design", Proceedings of the DESIGN 2016 14th International Design Conference, Dubrovnik, Croatia, pp. 975-984.

Fu, K. et al. (2013), "The Meaning of "Near" and "Far": The Impact of Structuring Design Databases and the Effect of Distance of Analogy on Design Output", Journal of Mechanical Design, Vol. 135 No. 2, pp. 1-12. https://doi.org/10.1115/1.4023158

Gero, J.S. and Kannengiesser, U. (2004), "Modelling Expertise of Temporary Design Teams”, Journal of Design Research, Vol. 4, pp. 1-13.

Goel, A.K. (1997), "Design, analogy, and creativity", IEEE Expert, Vol. 12 No. 3, pp. 62-70.

Gonçalves, M., Cardoso, C. and Badke-Schaub, P. (2016), "Inspiration choices that matter: the selection of external stimuli during ideation", Design Science, Vol. 2 No. 10, pp. 1-31. https://doi.org/10.1017/dsj.2016.10

Hirtz, J. et al. (2002), “A Functional Basis for Engineering Design: Reconciling and Evolving Previous Efforts", Research in Engineering Design, Vol. 13, pp. 65-82.

Howard, T.J., Dekoninck, E.A. and Culley, S.J. (2010), "The use of creative stimuli at early stages of industrial product innovation", Research in Engineering Design, Vol. 21 No. 4, pp. 263-274. https://doi.org/ 10.1007/s00163-010-0091-4

Jia, L. et al. (2019), "Testing ideation performance on a large set of designers: effects of analogical distance", International Journal of Design Creativity and Innovation. https://doi.org/10.1080/21650349.2019.1618736, In Press.

Kao, C.Y. (2014), "Exploring the relationships between analogical, analytical, and creative thinking", Thinking Skills and Creativity, Vol. 13, pp. 80-88. https://doi.org/10.1016/j.tsc.2014.03.006

Kennedy, E.B., Miller, D.J. and Niewiarowski, P.H. (2018), "Industrial and Biological Analogies Used Creatively by Business Professionals", Creativity Research Journal, Vol. 30 No. 1, pp. 54-66. https://doi.org/10.1080/10400419.2017.1411631

Landis, J.R. and Koch, G.G. (1977), “The measurement of observer agreement for categorical data”, Biometrics, Vol. 33 No. 1, pp. 159-174.

Lucero, A., Vaajakallio, K. and Dalsgaard, P. (2012), "The dialogue-labs method: process, space and materials as structuring elements to spark dialogue in co-design events", CoDesign International Journal of CoCreation in Design and the Arts, Vol. 8 No. 1, pp. 1-23. https://doi.org/10.1080/15710882.2011.609888

Malins, J. et al. (2014), "Supporting the early stages of the product design process: using an integrated collaborative environment", In: International Conference on Engineering and product design education, University of Twente, The Netherlands, pp. 166-171.

OIPEC (2016), OIPEC: Open innovation Platform for University-Enterprise Collaboration. [Online] Available at: http://www.oipec.eu/ [accessed 2017].

Ozkan, O. and Dogan, F. (2013), "Cognitive strategies of analogical reasoning in design: Differences between expert and novice designers", Design Studies, Vol. 34 No. 2, pp. 161-192. https://doi.org/10.1016/ j.destud.2012.11.006

Parvin, M. (2017), Improving ideas novelty based on OTSM-TRIZ model of contradiction, Mechanical Engineering. Milano: PhD Thesis, Politecnico di Milano.

Parvin, M., Cascini, G. and Becattini, N. (2017), "Information extracted from patents as creative stimuli for product innovation", Proceedings of the 21st International Conference on Engineering Design (ICED 17), Vancouver, Canada.

Saliminamin, S., Becattini, N. and Gaetano, C. (2019), "Sources of creativity stimulation for designing the next generation of technical systems: correlations with R\&D designers' performance", Research in Engineering Design, Vol. 30, pp. 133-153. https://doi.org/10.1007/s00163-018-0299-2

Shah, J.J., Smith, S.M. and Vargas-Hernandez, N. (2003), "Metrics for measuring ideation effectiveness", Design Studies, Vol. 24 No. 2, pp. 111-134.

The Biomimicry Institute. (2018), Ask Nature. [Online], Available at: AskNature.org. 